\title{
Field Study on the Air-Side Heat Transfer Performance of Copper Finned-Flat Tubes for Heavy-Duty Truck Radiators
}

\author{
Jose Canazas \\ School of Mechanical Engineering, Universidad Nacional de San Agustin, Arequipa 04000, Peru
}

Corresponding Author Email: jcanazas@unsa.edu.pe

https://doi.org/10.18280/ijht.390506

Received: 5 September 2021

Accepted: 25 October 2021

\section{Keywords:}

air-side, finned-flat tube, heat transfer, heavy-duty truck, radiator

\begin{abstract}
Heavy-duty truck cooling systems have been given low importance in the enhancement and research of heat transfer performance since off-highway conditions are hard to evaluate in laboratory essays or CFD studies. The present work is performed to evaluate the heat transfer performance of copper finned-flat tubes used in heavy-duty truck radiators. Parameters were measured in the field of two heavy-duty truck engines cooling systems. In both vehicles water is used as the cooling fluid. The results showed that the Air convective heat transfer coefficient and Overall heat transfer coefficient on the air side decreases as the Reynolds Number decreases and increases as passing through the first row to the fourth row. Additionally, the mass air flow and heat transfer rate have very high values in comparison from normal automotive radiators' operative conditions, since heavyduty truck radiators require a large heat transfer rate. The analysis presented in this paper was used for a heavy-duty truck radiator but can be extended to any equipment with finned flat tubes. A more accurate study should be done considering vibrations and different environmental conditions.
\end{abstract}

\section{INTRODUCTION}

In internal combustion engines systems, the lack of comprehensive thermal measurements is part of a fundamental problem. There are many variations on measured parameters such as temperature, heat flux and gas side velocity [1]. So that, currently automobile engines almost never reach the efficiency at which they were designed because of constant heat losses. The effectiveness of the water-cooling system increases with the increase in the circulation of the liquid, its maximum temperature and the amount of heat dissipated in the radiator per unit area. The effectiveness is evaluated by the power consumed to drive the fan and the pump, as well as by the dimensional and mass ratings [2, 3].

Automobile radiator performance has been studied for decades, but specifically heavy-duty truck radiators are overlooked. There are a lot of considerations on these kinds of radiators, since the off-highway conditions are completely different from laboratory essays or CFD studies. Mao et al. [4] analyzed the thermal performance of a heavy-duty truck radiator with modular cores by using CFD. Also, Mao et al. [5] presented an investigation on three subsystems of a heavyduty internal combustion engine by using CFD, where radiator surface temperature was analyzed. Eitel et al. [6] argued that aluminum compact radiators are more versatile than other radiators for heavy duty trucks. That is right but the biggest disadvantage of this type of radiator are the failures generated by vibrations of the internal combustion engine and the offhighway environment. Robin et al. [7] mentioned that it is very important that the heavy-duty truck radiators need to be optimized or redesigned to maintain a working temperature that allows maximum efficiency of the engine.

Finned tubes in any configuration are the most common model for automobile radiators. Kays and London [8] have investigated a lot of configurations of this kind of tube giving correlations for air side heat exchangers in plate fin tubes, wavy fins, circular tubes, etc. Webb [9] and Kumar et al. [10] developed a large number of geometries and empirical correlations and presented the principal advantages and developments technologies enhancement in finned tube heat exchangers. Yun et al. [11] and Liu et al. [12] investigated the performance of finned flat tubes in wet and frosting conditions respectively. The studies under any environmental condition allows interweaving the working conditions in any terrain, since heavy-duty trucks are able to work in extreme conditions Park et al. [13], Liu et al. [14] and Xie et al. [15] presented multiple considerations that must be taken into account when evaluating or designing a flat finned tube heat exchanger. They also suggested some technological improvements in geometry that are very influential on the thermodynamic properties of fluids.

Individual finned flat tubes in a flexible core radiator seems to be a relatively good solution, but the most promising, to maintain a good heat transfer performance without being hard damaged by the off-highway conditions. Flexible core radiators are taking part of heavy equipment instead of modular core radiators or compact aluminum radiators. Application of copper finned-flat tubes offer some advantages compared to the other types of heat exchangers. These tubes are able to be exchanged, cleaned and repaired quickly, so there are a lot of time and money savings in maintenance. The most important characteristic of these tubes is the high heat transfer area per unit length that keeps the performance of the engine cooling system. Some studies have done using this kind of heat exchangers in other applications. Du et al. [16] presented an enhancement to the heat transfer performance of 
individual wavy finned flat tubes with vortex generators. Duan et al. [17] investigated the heat transfer performance of an individual wavy finned flat tube heat exchanger in a power plant by using CFD.

The present study is conducted to evaluate radiators with copper finned-flat tubes of two heavy-duty trucks since there are no research works done before in this specific area. Geometric tube considerations are also developed to evaluate these radiators. And the heat transfer performance per row is calculated due to air-side temperature variations and geometric considerations.

\section{METHODOLOGY}

\subsection{Technical data}

In this study, the scope of the work is limited. There are a lot of considerations about the environment, the climate, and the current performance of the equipment. Before the experimental measurements, engines and radiators have received maintenance to minimize heat losses. The tested radiators are installed next to two heavy-duty diesel engines shown in Table 1. The radiators are installed with the engine in the truck shop facility by using a suitable lifting device. The radiator weighs approximately 5000 to $8000 \mathrm{~kg}$ in heavy-duty trucks. The lifting device is used in order to position the radiator to the chassis. Fastening elements such as bolts and links are installed to the frame. Finally, the hoses and clamps are installed at the inlet and outlet ports.

The engines are turbocharged and after cooled. Their working hours range from 12 to 20 hours per day. Between the engine and radiator there are some components that regulate the operating parameters: thermostats, gaskets, water pump, hose clamp, and fan.

Table 1. Specifications of heavy-duty truck engines

\begin{tabular}{ccc}
\hline Parameter & Engine 1 & Engine 2 \\
\hline Configuration & V20 & V16 \\
Maximum Power (kW) & 2,990 & 1,977 \\
Rated Speed Max. Power (RPM) & 1,750 & 1,750 \\
Maximum Torque (Nm) & 19,600 & 12,899 \\
Rated Speed Max. Torque (RPM) & 1,300 & 1,300 \\
\hline
\end{tabular}

Table 2. Specifications of radiators

\begin{tabular}{ccc}
\hline Parameter & Radiator 1 & Radiator 2 \\
\hline Number of stages & 2 & 2 \\
Number of tubes per stage & 568 & 384 \\
Tube length (mm) & 1,444 & 1,158 \\
Finned section length (mm) & 1,382 & 1,096 \\
Tube and fin material & Copper & Copper \\
\hline
\end{tabular}

The radiators consist of two principal parts: The heat transfer section and the structural section shown on Figure 1(a). The specifications are shown in Table 2. The heat transfer section is made up of the copper finned-flat tubes. These are installed with rubber seals to the structural section shown on Figure 1(b). These are prone to vibrations caused by the engine, so usually have an intermediate support. The structural section is made up of hard steel plates. There are three tanks (top, bottom and intermediate) where the tubes are installed between each other. There are performance components in the structural section as drain plug, pressure cap, inlet from engine, and outlet to engine shown in Figure 1(c).

A model of a finned-flat tube section is given on Figure 2. All the symbols that are shown are the structural parameters described in Table 3.

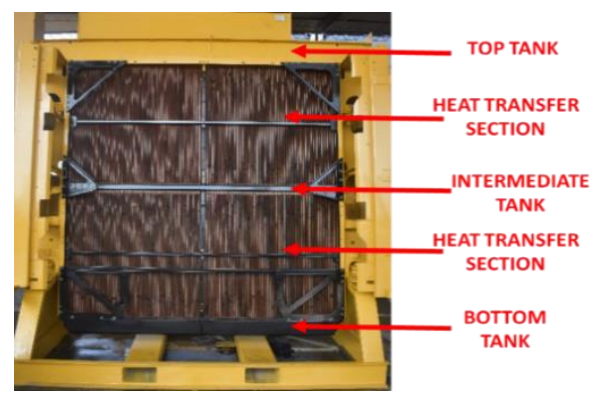

(a)

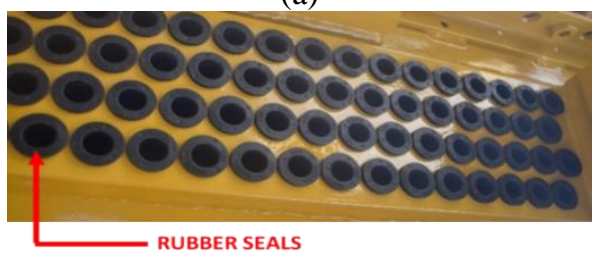

(b)

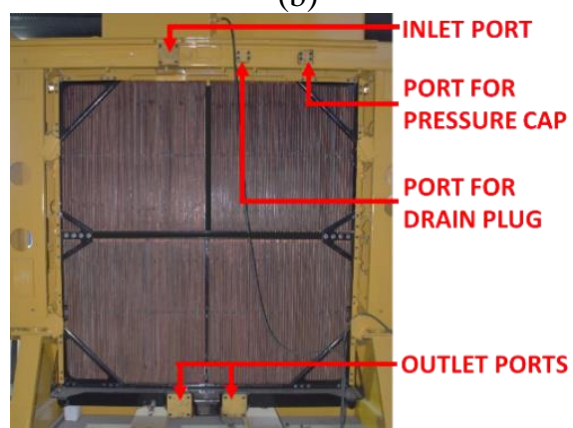

(c)

Figure 1. Heavy duty truck radiator schematic

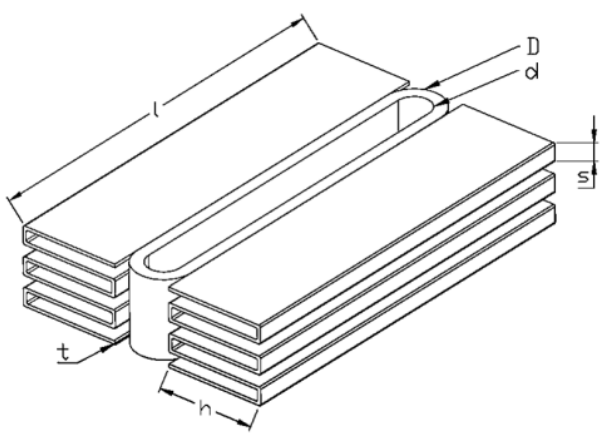

Figure 2. Geometry of finned-flat tube section

Table 3. Structural parameters of finned-flat tubes

\begin{tabular}{ccc}
\hline Parameter & Symbol & Value \\
\hline Fin thickness $(\mathrm{mm})$ & $\mathrm{t}$ & 0.2 \\
Fin Height $(\mathrm{mm})$ & $\mathrm{h}$ & 5.8 \\
Fin Length $(\mathrm{mm})$ & 1 & 23.0 \\
Fin spacing $(\mathrm{mm})$ & $\mathrm{s}$ & 0.7 \\
Flat tube outside diameter $(\mathrm{mm})$ & $\mathrm{D}$ & 3.5 \\
Flat tube inside diameter $(\mathrm{mm})$ & $\mathrm{d}$ & 2.0 \\
\hline
\end{tabular}

\subsection{Experimental procedure}

In this study the parameters were measured in the field. The study was developed in the southwest area of the department 
of Arequipa, in Peru. The environmental parameters are shown in Table 4.

Table 4. Environmental parameters

\begin{tabular}{cc}
\hline Parameter & Value \\
\hline Height above mean sea level & $1200 \mathrm{~m}$ \\
Average relative humidity & $74 \%$ \\
Average ambient temperature & $27^{\circ} \mathrm{C}$ \\
\hline
\end{tabular}

Every heavy-duty equipment usually has a control monitoring system that shows information about the cooling system like temperature and performance of components. The experimental set-up shown in Figure 3 has measurement instruments to evaluate the radiator performance independently of the other system before mentioned. The accuracy for the instruments used to evaluate the radiators are shown in Table 5.

Table 5. Instruments range and accuracy

\begin{tabular}{ccc}
\hline Instrument & Range & Accuracy \\
\hline Joint Pipe Temp. Sensor & $40 \sim 150^{\circ} \mathrm{C}$ & $\pm 1^{\circ} \mathrm{C}$ \\
Flow meter & $0 \sim 200 \mathrm{~m}^{3} / \mathrm{hr}$ & $\pm 0.1 \mathrm{~m}^{3} / \mathrm{hr}$ \\
Temperature sensor & $0 \sim 100^{\circ} \mathrm{C}$ & $\pm 0.1^{\circ} \mathrm{C}$ \\
\hline
\end{tabular}

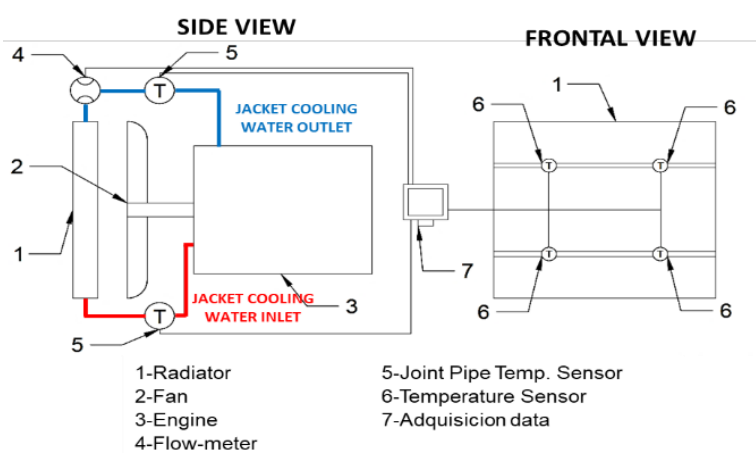

Figure 3. Schematic diagram of experimental set-up

The fan is attached to a hydraulic motor. This motor is programmed to increase or reduce rotation speed in function of: Jacket water coolant temperature, Charge air Cooler coolant temperature, Transmission lubrication temperature, Torque converter oil temperature, Brake oil temperature, Brake status, Ground speed, Output status of the hoist system.

The output parameters measured are shown in Figure 4. The measured points were taken as a function of engine rotation speed. It is considered nine points from each Engine - Radiator group from 1300 RPM to 1700 RPM.

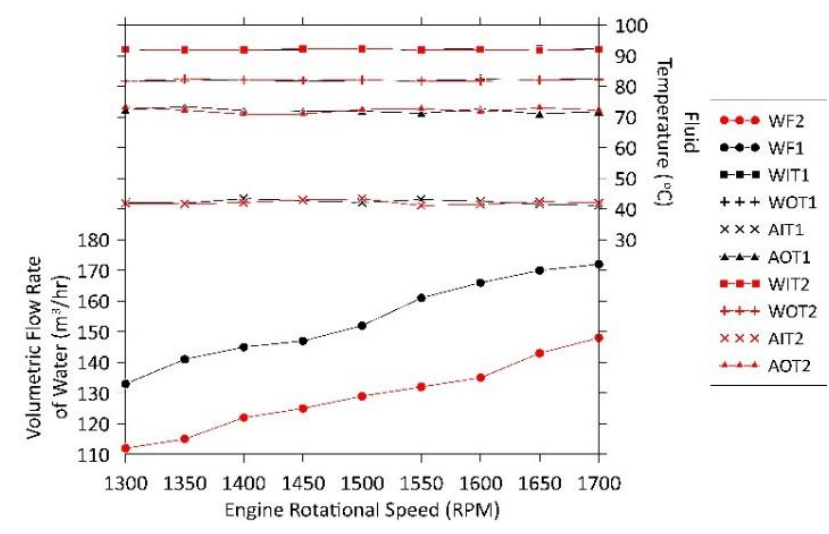

Figure 4. Experimental taken data
In the description WF means Water Flow, WIT means Water Inlet Temperature, WOT means Water Outlet Temperature, AIT means Air Inlet Temperature, and AOT means Air Outlet Temperature. Characteristics ended by 1 are the Engine 1 - Radiator 1 group, and ended by 2 are the Engine 2 - Radiator 2 group. These measured points are not completely accurate due to deviations in engine acceleration. It has been adjusted since the heavy duty trucks tested have an Engine Control Module (ECM) system that can be connected to a computer and digitally obtain engine rotational speed. So that the truck operator can partially simulates a dynamometer.

\subsection{Engineering analysis}

\subsubsection{Finned-flat tube characterization}

The geometries of the finned flat tube in the water side are a very common flat tube with rounded ends. On the other hand, on the air side some considerations are needed. Kays and London give some geometrical properties for some finned circular and flat tubes [8]. However, in this situation every tube is considered as an individual heat exchanger.

Air-side heat transfer area per unit length in Eq. (6) is the first step to relate the heat of the process and the overall heat transfer coefficient. It is necessary to parametrize a referential longitudinal section given in Eq. (1) that is a section of the flat tube considering the length of a closed and an opened fin space "s" with fin thickness " $t$ ".

$$
L_{r e f}=2(s+t)
$$

Air-side heat transfer area is calculated by considering all surfaces where air will pass in the longitudinal section: frontal and longitudinal surfaces of fin and the external area of the flat tube. So is needed to solve the frontal area in Eq. (2), longitudinal area in Eq. (3) and external tube area in Eq. (4). It is calculated as follows:

$$
\begin{gathered}
A_{f}=4[(h+t) t+s t] \\
A_{l}=2 l(2 s+2 h+t) \\
A_{t}=\pi D L_{r e f} \\
A_{T}=2\left(A_{f}+A_{l}\right)+A_{t} \\
a^{\prime \prime}=\frac{A_{T}}{L_{r e f}}
\end{gathered}
$$

Hydraulic diameter of the heat exchanger in the water side in Eq. (7) is calculated with a simple relation between the wet surface and the flow area inside of the flat tube.

$$
D_{h, w}=4\left(\frac{d(l-d)+\pi \frac{d^{2}}{4}}{2(l-d)+2 \pi \frac{a}{2}}\right)
$$

In the air side, hydraulic diameter in Eq. (8) will be evaluated in the referential longitudinal section as an average of the two hydraulic diameters in the closed and opened fin space of the longitudinal section. 


$$
D_{h, a}=\frac{4}{2}\left(\frac{s h}{2(s+h)}+\frac{s h}{s+2 h}\right)
$$

\subsubsection{Heat transfer analysis}

The water mass flow is defined in Eq. (9):

$$
\dot{m}_{w}=\dot{V}_{w} \rho_{w}
$$

The heat balance in the air side and the water side is as follows in Eq. (10) and Eq. (11) respectively:

$$
\begin{gathered}
Q=\dot{m}_{w} c_{w}\left(T_{W O}-T_{W I}\right) \\
Q=\dot{m}_{a} c_{a}\left(T_{A I}-T_{A O}\right)
\end{gathered}
$$

To solve that every tube is considered as an individual heat exchanger, it is needed to separate every row. Figure 5 shows a sectioned projected view in the air side that considers the mass air flow distribution. The purpose is to determine the estimated outlet temperatures of each heat exchanger.

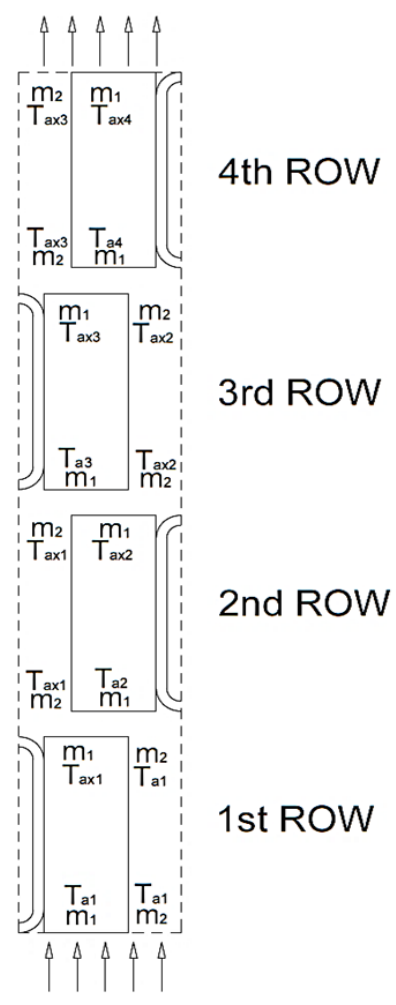

Figure 5. Schematic of flow balance for each row

Eq. (12) represents the mass air flow passing through the fins and spaces between the finned tubes in a longitudinal section. Eq. (13) is the mass air flow through the fins and Eq. (14) is the mass air flow through the space between finned tubes.

$$
\begin{gathered}
\dot{m}_{a 1,2}=\frac{\left(\frac{\dot{m}_{a}}{4}\right) 9.75}{19.5\left(\frac{n_{\text {tubes }}}{8}-1\right)+\frac{19.5}{2}} \\
\dot{m}_{a 1}=\frac{6}{9.75} \dot{m}_{a 1,2}
\end{gathered}
$$

$$
\dot{m}_{a 2}=\frac{3.75}{9.75} \dot{m}_{a 1,2}
$$

Air side heat balance in the first row is developed in Eq. (15), in the second row is developed in Eq. (16), in the third row is developed in Eq. (17), and in the fourth row is developed in Eq. (18).

$$
\begin{gathered}
\dot{m}_{a 1} h_{T a x 1}+\dot{m}_{a 2} h_{T a 1}=\dot{m}_{a 2} h_{T a x 1}+\dot{m}_{a 1} h_{T a 2} \\
\dot{m}_{a 1} h_{T a x 2}+\dot{m}_{a 2} h_{T a x 1}=\dot{m}_{a 2} h_{T a x 2}+\dot{m}_{a 1} h_{T a 3} \\
\dot{m}_{a 1} h_{T a x 3}+\dot{m}_{a 2} h_{T a x 2}=\dot{m}_{a 2} h_{T a x 3}+\dot{m}_{a 1} h_{T a 4} \\
\dot{m}_{a 1} h_{T a x 4}+\dot{m}_{a 2} h_{T a x 3}=\dot{m}_{a 2} h_{T a x 4}+\dot{m}_{a 1} h_{T_{A O}}
\end{gathered}
$$

The mass velocity and Reynolds number on both sides is evaluated in Eq. (19) and (20). The mass velocity is considered per unit on each side. On the water side per tube, and on the air side per fin spacing.

$$
\begin{gathered}
G=\frac{\dot{m}_{\text {unit }}}{A_{\text {unit }}} \\
\operatorname{Re}=\frac{D_{h} G}{\mu}
\end{gathered}
$$

On the water side, the Nusselt number will be calculated with the Gnielinski correlation by Eq. (21), which is presented by Bejan [18]. Gnielinski [19] developed this Hausen type correlation to take a large range of liquids with a good accuracy, without considering friction factor.

$$
\begin{aligned}
& N u_{w}=0.012\left(\operatorname{Re}_{w}^{0.87}-280\right) \operatorname{Pr}_{w}^{0.4} \\
& 1.5 \leq \operatorname{Pr} \leq 500 \ldots 3 \times 10^{3} \leq \operatorname{Re} \leq 10^{6}
\end{aligned}
$$

Convective heat transfer coefficient of water is defined in Eq. (22):

$$
h_{w}=\frac{N u_{w} k_{w}}{D_{h, w}}
$$

LMTD Method is considered as a model to evaluate the air side heat transfer coefficient, considering that will result a different temperature per row. In Eq. (23) " $n$ " means the row number evaluated, and " $F$ " as the crossflow factor.

$$
\Delta T_{l m}=F \times \frac{\left(T_{W I}-T_{a x n}\right)-\left(\frac{T_{W I}+T_{W O}}{2}+T_{a n}\right)}{\ln \left[\frac{T_{W I}-T_{a x n}}{\frac{T_{W I}+T_{W O}}{2}+T_{a n}}\right]}
$$

Overall Heat Transfer Coefficient is defined in Eq. (24):

$$
U=\frac{Q}{L_{\text {finned }} \times a^{"} \times \Delta T_{l m}}
$$


Convective heat transfer coefficient of air has to be calculated with the overall heat transfer coefficient, surface fin effectiveness and relation between water side heat transfer surface and air side heat transfer surface.

Fin effectiveness parameter in Eq. (25) is calculated with air-side convective heat transfer coefficient, heat transfer coefficient of copper and the fin thickness.

Fin efficiency in Eq. (26) is calculated with the fin effectiveness parameter, fin height and fin thickness.

Surface effectiveness of the fins in Eq. (27) is part of the heat transfer coefficient balance, it is calculated with fin efficiency and Fin area/total area relation.

$$
\begin{gathered}
m_{f}=\sqrt{\frac{2 h_{a}}{k_{\text {copper }} t}} \\
\eta_{f}=\frac{\tanh \left(m_{f}(h+t)\right)}{m_{f}(h+t)} \\
\eta_{o}=1-\frac{A_{f}}{A_{T}}\left(1-\eta_{f}\right)
\end{gathered}
$$

So, convective heat transfer coefficient of the air is defined in Eq. (28):

$$
h_{a}=\frac{1}{\eta_{o}\left(\frac{1}{U}-\frac{1}{h_{w} \frac{A_{w}}{A_{a}}}\right)}
$$

\subsubsection{Uncertainty analysis}

The uncertainties associated with the Heat transfer rate (Eq. (29)), mass air flow (Eq. (30)), Reynolds Number (Eq. (31)), Air side Overall heat transfer coefficient (Eq. (32)), Air side convective heat transfer coefficient (Eq. (34)) were calculated by the following equations [20]. The uncertainties are summarized in Table 6.

Table 6. Uncertainties for the calculated parameters

\begin{tabular}{cc}
\hline Calculated Parameter & Uncertainty (\%) \\
\hline Mass Air Flow & 0.17 \\
Reynolds Number & 0.22 \\
Air Convective Heat Transfer Coefficient & 5.12 \\
Air-side Overall Heat Transfer Coefficient & 2.95 \\
Heat Transfer Rate & 1.21 \\
\hline
\end{tabular}

$$
\begin{aligned}
& \varepsilon_{Q}=\sqrt{\left(\frac{\partial Q}{\partial \dot{m}_{w}} \varepsilon_{\dot{m}_{w}}\right)^{2}+\left(\frac{\partial Q}{\partial c_{w}} \varepsilon_{c_{w}}\right)^{2}+\left(\frac{\partial Q}{\partial \Delta T_{w}} \varepsilon_{\Delta T_{w}}\right)^{2}} \\
& =\sqrt{\left(c_{w} \cdot \Delta T_{w} \cdot \varepsilon_{\dot{m}_{w}}\right)^{2}+\left(\dot{m}_{w} \cdot \Delta T_{w} \cdot \varepsilon_{c_{w}}\right)^{2}+\left(c_{w} \cdot \dot{m}_{w} \cdot \varepsilon_{\Delta T_{w}}\right)^{2}}
\end{aligned}
$$

where, $Q$ is the heat transfer rate, $m_{w}$ is the mass water flow rate, $c_{w}$ is the water specific heat, $\Delta T_{w}$ is temperature variation between the outlet and inlet temperatures in the water side, and $\varepsilon_{Q}, \varepsilon_{m w}, \varepsilon_{c w}$ and $\varepsilon_{\Delta T w}$ are the uncertainties associated with the heat transfer rate, mass flow rate, specific heat and variation between the outlet and inlet temperatures in the water side, respectively.

$$
\begin{aligned}
& \varepsilon_{\dot{m}_{a}}=\frac{\sqrt{\left(\frac{\partial \dot{m}_{a}}{\partial Q} \varepsilon_{Q}\right)^{2}+\left(\frac{\partial \dot{m}_{a}}{\partial c_{a}} \varepsilon_{c_{a}}\right)^{2}+\left(\frac{\partial \dot{m}_{a}}{\partial \Delta T_{a}} \varepsilon_{\Delta T_{a}}\right)^{2}}}{c_{a}{ }^{2} \Delta T_{a}^{2}} \\
& =\frac{\sqrt{\left(c_{a} \cdot \Delta T_{a} \cdot \varepsilon_{Q}\right)^{2}+\left(\Delta T_{a} \cdot Q \cdot \varepsilon_{c_{a}}\right)^{2}+\left(c_{a} \cdot Q \cdot \varepsilon_{\Delta T_{a}}\right)^{2}}}{c_{a}{ }^{2} \Delta T_{a}{ }^{2}}
\end{aligned}
$$

where, $m_{a}$ is the mass air flow rate, $Q$ is the heat transfer rate, $c_{a}$ is the air specific heat, $\Delta T_{a}$ is temperature variation between the outlet and inlet temperatures in the air side, and $\varepsilon_{m w}, \varepsilon_{Q}, \varepsilon_{c a}$ and $\varepsilon_{\triangle T a}$ are the uncertainties associated with mass air flow rate, heat transfer rate, air specific heat and variation between the outlet and inlet temperatures in the air side, respectively.

$$
\begin{aligned}
& \varepsilon_{\operatorname{Re}}=\frac{\sqrt{\left(\frac{\partial \operatorname{Re}}{\partial D_{h}} \varepsilon_{D_{h}}\right)^{2}+\left(\frac{\partial \operatorname{Re}}{\partial G} \varepsilon_{G}\right)^{2}+\left(\frac{\partial \operatorname{Re}}{\partial \mu} \varepsilon_{\mu}\right)^{2}}}{\mu^{2}} \\
& =\frac{\sqrt{\left(\mu \cdot G \cdot \varepsilon_{D_{h}}\right)^{2}+\left(\mu \cdot D_{h} \cdot \varepsilon_{G}\right)^{2}+\left(D_{h} \cdot G \cdot \varepsilon_{\mu}\right)^{2}}}{\mu^{2}}
\end{aligned}
$$

where, $\mathrm{Re}$ is the Reynolds Number, $D_{h}$ is the Hydraulic diameter, $G$ is the mass flow velocity, $\mu$ is the dynamic viscosity, and $\varepsilon_{R e}, \varepsilon_{D h}, \varepsilon_{G}, \varepsilon_{\mu}$ are the uncertainties associated with Reynolds Number, Hydraulic diameter, mass flow velocity and dynamic viscosity, respectively.

$$
\begin{aligned}
& \varepsilon_{U_{a}}=\frac{\sqrt{\left(\frac{\partial U_{a}}{\partial Q} \varepsilon_{Q}\right)^{2}+\left(\frac{\partial U_{a}}{\partial A} \varepsilon_{A}\right)^{2}+\left(\frac{\partial U_{a}}{\partial \Delta T_{l m}} \varepsilon_{\Delta T_{l m}}\right)^{2}}}{A^{2} \Delta T_{l m}{ }^{2}} \\
& =\frac{\sqrt{\left(\Delta T_{l m} \cdot A \cdot \varepsilon_{Q}\right)^{2}+\left(\Delta T_{l m} \cdot Q \cdot \varepsilon_{A}\right)^{2}+\left(Q \cdot A \cdot \varepsilon_{\Delta T_{l m}}\right)^{2}}}{A^{2} \Delta T_{l m}{ }^{2}}
\end{aligned}
$$

where, $U_{a}$ is the Overall Heat Transfer coefficient on the airside, $Q$ is the heat transfer rate, $A$ is the Heat Transfer Surface Area, $\Delta T_{l m}$ is $\log$ mean temperature difference, and $\varepsilon_{U a}, \varepsilon_{Q}, \varepsilon_{A}$, $\varepsilon_{\Delta T I m}$ are the uncertainties associated with the overall heat transfer coefficient on the air side, heat transfer rate, heat transfer surface area and log mean temperature difference, respectively.

$$
\begin{aligned}
& S=\frac{h_{w} A_{w}}{A_{a}} \\
& \varepsilon_{S}=\frac{\sqrt{\left(A_{w} \cdot A_{a} \cdot \varepsilon_{h_{w}}\right)^{2}+\left(A_{a} \cdot h_{w} \cdot \varepsilon_{A_{w}}\right)^{2}+\left(h_{w} \cdot A_{w} \cdot \varepsilon_{A_{a}}\right)^{2}}}{A_{a}{ }^{2}}
\end{aligned}
$$

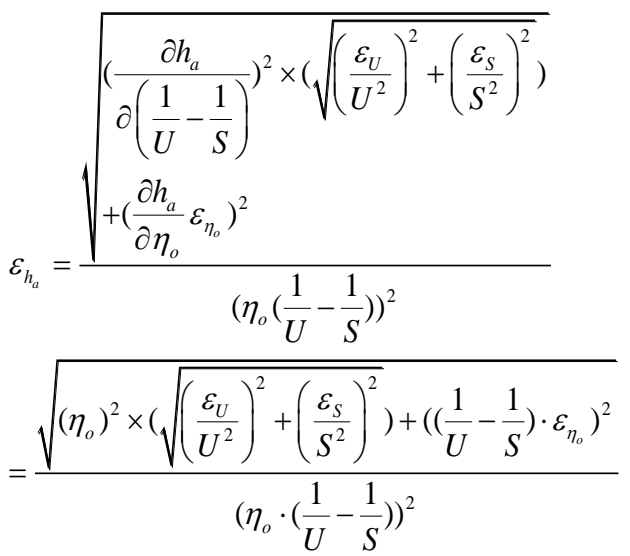


where, $h_{a}$ is the Air convective heat transfer coefficient, $U$ is the Overall heat transfer coefficient, $S$ is the relation between $h_{w}$ (Water convective heat transfer coefficient), $A_{w}$ (Water side surface area) and $A_{a}$ (Air side surface area) shown in Eq. (33), $\eta_{o}$ is the Surface fin effectiveness, and $\varepsilon_{h a}, \varepsilon_{U}, \varepsilon_{S}, \varepsilon_{\eta o}$ are the uncertainties associated with the air convective heat transfer coefficient, relation between $h_{w}, A_{w}$ and $\mathrm{A}_{\mathrm{a}}$ and surface fin effectiveness, respectively.

\section{RESULTS}

In this section, the air-side heat transfer performance of the two heavy-duty truck radiators is developed considering the air convective heat transfer coefficient and overall heat transfer coefficient in the air-side versus the Air Reynolds number. The heat transfer rate is evaluated with the air mass flow rate to identify the capacities from each Engine - Radiator group. Additionally, Table 7 shows a comparison between the results obtained and normal automotive radiators' operative conditions [21] that were collected and summarized from past literature by D. Ray \& D. Das.

\subsection{Air convective heat transfer coefficient and overall heat transfer coefficient on the air-side}

The effect of the Air Convective Heat Transfer Coefficient per row is shown in Figure 6(a) for the Engine 1- Radiator 1 group and in Figure 6(b) for the Engine 2 - Radiator 2 group. And the effect of the Overall heat transfer coefficient on the air-side per row is shown in Figure 7(a) for the Engine 1Radiator 1 group and in Figure 7(b) for the Engine 2 - Radiator 2 group. In both radiators, the heat transfer coefficient and overall heat transfer coefficient decreases with decreasing the

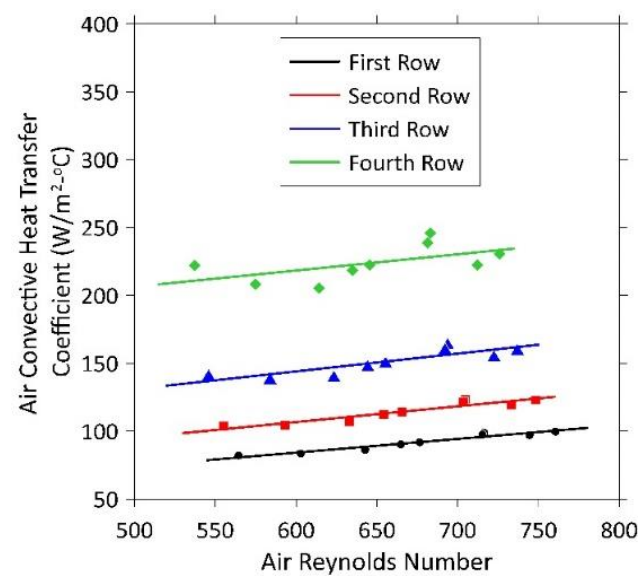

(a) Engine 1 - Radiator 1 Group
Air Reynolds number and increases as passing through the first row to the fourth row. Note that the three first rows have a similar behavior and the fourth row has higher heat transfer coefficients. In the Engine 1 - Radiator 1 Group Reynolds number ranges presented are from 537 in the fourth row to 761 in the first row. In the Engine 2 - Radiator 2 Group Reynolds number ranges presented are from 812 in the fourth row to 1157 in the first row.

In Figure 6(a) the maximum value of the Air convective heat transfer coefficient is in the fourth row with a value of $250 \mathrm{~W} / \mathrm{m}^{2}-{ }^{\circ} \mathrm{C}$, and the minimum value of $75 \mathrm{~W} / \mathrm{m}^{2}-{ }^{\circ} \mathrm{C}$ in the first row. In Figure 6(b) the maximum value of the Air convective heat transfer coefficient is in the fourth row with a value of $440 \mathrm{~W} / \mathrm{m}^{2}-^{\circ} \mathrm{C}$, and the minimum value of 110 $\mathrm{W} / \mathrm{mm}^{2}-^{\circ} \mathrm{C}$ in the first row. The variation between the Engine 1 - Radiator 1 group and the Engine 2 - Radiator 2 group values is based principally on the water convective heat transfer coefficient that is function of the water Reynolds Number, and it is function of the water mass flow rate that increases with a higher jacket cooling water demand. Also is considered the Overall heat transfer coefficient in the air-side described below.

In Figure 7(a) the maximum value of the Overall heat transfer coefficient on the air-side is in the fourth row with a value of $190 \mathrm{~W} / \mathrm{mm}^{2}-^{\circ} \mathrm{C}$, and the minimum value of 70 $\mathrm{W} / \mathrm{m}^{2}-^{\circ} \mathrm{C}$ in the first row. In Figure $7(\mathrm{~b})$ the maximum value of the Overall heat transfer coefficient on the air side is in the fourth row with a value of $300 \mathrm{~W} / \mathrm{m}^{2}-{ }^{\circ} \mathrm{C}$, and the minimum value of $100 \mathrm{~W} / \mathrm{m}^{2}-{ }^{\circ} \mathrm{C}$ in the first row. The variation between the Engine 1 - Radiator 1 group and the Engine 2 - Radiator 2 group values is based on the heat transfer rate, that is a consequence of the radiator and diesel engine sizing. It is also considered that the tubes used in the first group have a greater length than those of the second group.

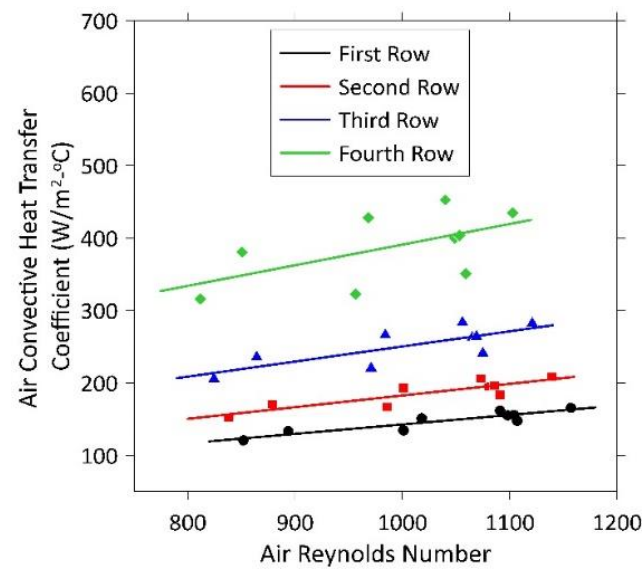

(b) Engine 2 - Radiator 2 Group

Figure 6. Air convective heat transfer coefficient vs air Reynolds number

Table 7. Comparison between operative conditions and data obtained

\begin{tabular}{|c|c|c|c|c|}
\hline \multirow{2}{*}{ Parameters } & \multicolumn{2}{|c|}{ Operative Conditions [21] } & \multicolumn{2}{|c|}{ Data Obtained } \\
\hline & Min & Max & Min & Max \\
\hline Air Inlet Temperature $\left({ }^{\circ} \mathrm{C}\right)$ & 15 & 75 & 41 & 43 \\
\hline Air Reynolds Number & 500 & 4,000 & 530 & 1,170 \\
\hline Air Convective Heat Transfer Coefficient $\left(\mathrm{W} / \mathrm{m}^{2}-^{\circ} \mathrm{C}\right)$ & 0 & 20 & 40 & 66 \\
\hline Air mass flow rate $(\mathrm{kg} / \mathrm{s})$ & 200 & 350 & 80 & 450 \\
\hline Overall Heat Transfer Coefficient on the Air Side $\left(\mathrm{W} / \mathrm{m}^{2}-{ }^{\circ} \mathrm{C}\right)$ & 75 & 240 & 70 & 300 \\
\hline Heat Transfer Rate $(\mathrm{kW})$ & 18 & 165 & 1,200 & 1,900 \\
\hline
\end{tabular}




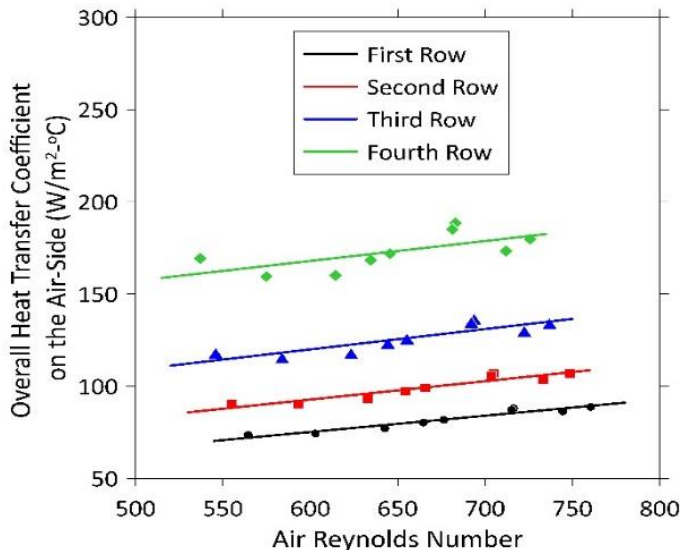

(a) Engine 1 - Radiator 1 Group

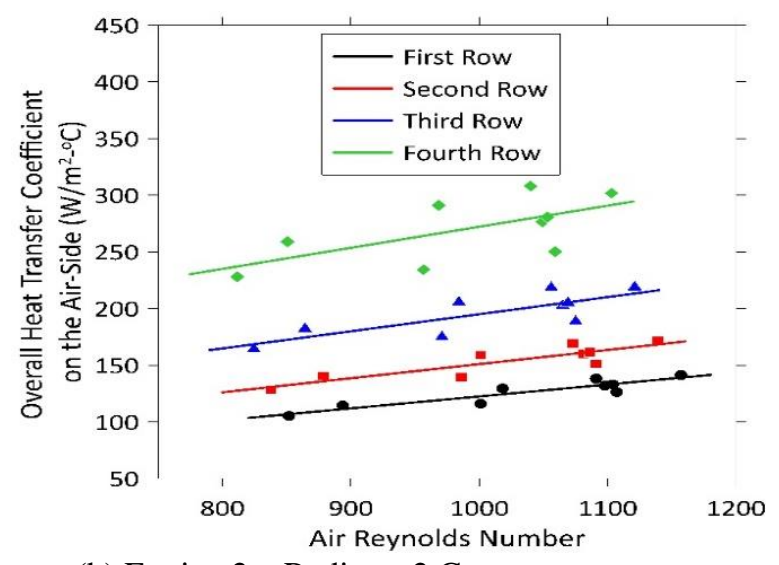

(b) Engine 2 - Radiator 2 Group

Figure 7. Overall heat transfer coefficient on the air-side vs air Reynolds number

The trends of heat transfer coefficients in the group 1 and group 2 are different. Taking into account that both groups have four rows, the trends should be similar. The main reason is that these radiators has been designed considering the space already determined for the heavy duty truck. So, the auxiliary components of the engine cooling system are working in different ranges on the two vehicles

In comparison with Table 7, the results of Air Convective Heat Transfer Coefficient and Overall Heat Transfer Coefficient on the air-side are close to the operative conditions in automotive radiators. The convective heat transfer is lower than normal conditions, but it can be explained because these normal conditions are considering the coefficient on the airside of the entire radiator as an average. Heavy-duty truck radiators sizes are large in comparison with automotive radiators.

These huge radiators are usually composed of large modules or in this case finned flat tubes, therefore the heat transfer analysis must be developed taking the modules or tubes as individual heat exchangers as mentioned above. In any calculation of a heat exchanger, it is recommended to separate by sections because if an average working temperature is considered then the results obtained will be far from reality. In other words, if an analytical study is carried out, it is recommended to consider differentials parts of adequate sizes. And in a numerical study should be used computational fluid dynamics. In the same way, a general Colburn factor cannot be considered for each geometry because the thermophysical conditions of air and water influence this value.

\subsection{Heat transfer rate}

The effect of the heat transfer rate per Engine - Radiator group is shown in Figure 8. Heat transfer rate increases with increasing mass air flow rate. Engine 1 - Radiator 1 Group has a higher heat transfer rate than Engine 2 - Radiator 2 Group, since the jacket cooling water system of Engine 1 requires more power than Engine 2.

In comparison with Table 7, the minimum heat transfer rate in obtained data is more than 50 times higher than operative conditions. Also, The Air mass flow rate in operative conditions is lower than obtained data. The main reason is that automotive radiators require less power in comparison with a heavy-duty truck radiator. The sizing of the engine, fan and jacket water pump is also a parameter to differentiate the radiators.

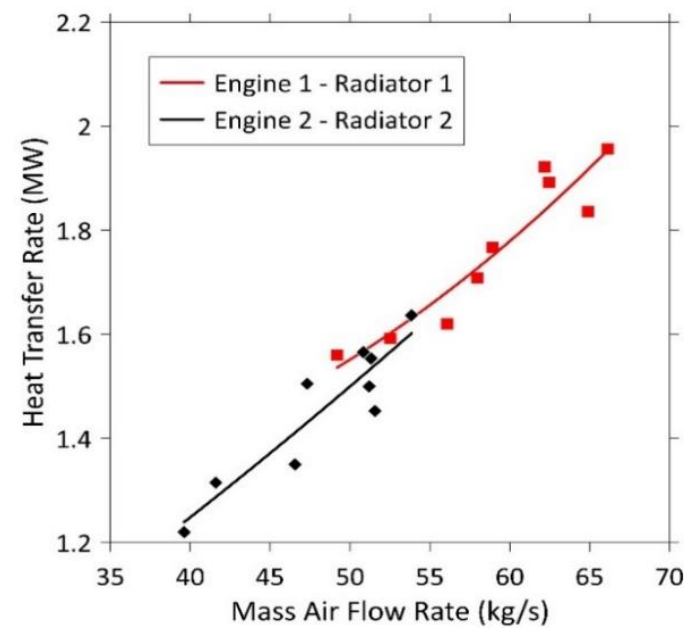

Figure 8. Heat transfer rate vs mass air flow rate

\section{CONCLUSIONS}

In this paper, it is shown the air side heat transfer performance of copper finned-flat tubes in flexible core radiators for heavy-duty trucks that has been evaluated in the field. The following are the key findings of this study:

-The thermal design of the two engine-radiator groups evaluated is not uniform. This is because there are variations of the maximum and minimum Reynolds number in both cases. The term "uniform" means a more effective cooling performance with less noise. So that the radiators must be redesigned [7] to achieve a good performance.

-The air convective heat transfer coefficient that was obtained is lower than in conventional compact aluminum radiators [6]. This is because finned-flat tube radiators have a greater heat transfer surface per unit length. And copper as a material of fins increases the fin efficiency.

-The radiator was tested with water as the coolant. Then the results obtained from the Air-side heat transfer coefficient are higher. If water had been used with some other additive or nanofluids [21] the result would be less noise in the variations of this coefficient and thus avoid an irregular behavior.

-The electronic fan drive system has many deviations. Since the hydraulic motor has been programmed to be in constant change due to the other equipment besides the radiator. Therefore, maintaining a stable behavior of the measures taken in the field is very difficult. 
It is recommended that for a future study the thermal capacity of these copper finned-flat tubes can be analyzed on a test bench with multiple environmental conditions, to be able to identify if this type of design has better working conditions in different environments. Also, this test bench should be integrated with a system that generates the vibrations of the internal combustion engine and the environment, to be more severe and identify if the structural behavior influences the heat transfer of these radiators.

\section{REFERENCES}

[1] Borman, G., Nishiwaki, K. (1987). Internal-combustion engine heat transfer. Progress in Energy and Combustion Science, 13(1): 1-46. https://doi.org/10.1016/03601285(87)90005-0

[2] Jováj, M.S. (1982). Motores de Automóvil, Editorial MIR Moscú - Latinoamérica.

[3] Heywood, J.B. (2018). Internal Combustion Engine Fundamentals. McGraw-Hill, New York.

[4] Mao, S., Cheng C., Li, X., Michaelides, E. (2010). Thermal/structural analysis of radiators for heavy-duty trucks. Applied Thermal Engineering, 30(11-12): 14381446.

https://doi.org/10.1016/j.applthermaleng.2010.03.003

[5] Mao, S., Feng, Z., Michaelides, E. (2010). Off-highway heavy-duty truck under-hood thermal analysis. Applied Thermal Engineering, 30(13): 1726-1733. https://doi.org/10.1016/j.applthermaleng.2010.04.002

[6] Eitel, J., Woerner, G., Horoho, S., Mamber, O. (1999). The aluminum radiator for heavy duty trucks. SAE Technical Paper Series. https://doi.org/10.4271/1999-013721

[7] Robin, P., Hariram, V., Subramanian, M. (2017). Probabilistic finite element analysis of a heavy duty radiator under internal pressure loading. Journal of Engineering Science and Technology, 12(9): 2438-2452.

[8] Kays, W.M., London, A.L. (1998). Compact Heat Exchangers. KriegerPub. Co., Malabar, FL.

[9] Webb, R.L. (1980). Air-side heat transfer in finned tube heat exchangers. Heat Transfer Engineering, 1(3): 33-49. https://doi.org/10.1080/01457638008939561

[10] Saha, S.K., Ranjan, H., Emani, M.S., Bharti, A.K. (2020). Heat transfer enhancement in externally finned tubes and internally finned tubes and annuli. Springer Briefs in Applied Sciences and Technology. https://doi.org/10.1007/978-3-030-20748-9

[11] Liu, X., Yu, J., Yan, G. (2019). An experimental study on the air side heat transfer performance of the perforated fin-tube heat exchangers under the frosting conditions. Applied Thermal Engineering, 166: 114634. https://doi.org/10.1016/j.applthermaleng.2019.114634

[12] Yun, R., Kim, Y., Kim, Y. (2009). Air side heat transfer characteristics of plate finned tube heat exchangers with slit fin configuration under wet conditions. Applied Thermal Engineering, 29(14-15): 3014-3020. https://doi.org/10.1016/j.applthermaleng.2009.03.017

[13] Park, Y.G., Jacobi, A.M. (2009). Air-side heat transfer and friction correlations for flat-tube louver-fin heat exchangers. ASME Journal of Heat Transfer, 131(2): 021801. https://doi.org/10.1115/1.3000609

[14] Liu, X., Yu, J., Yan, G. (2016). A numerical study on the air-side heat transfer of perforated finned-tube heat

exchangers with large fin pitches. International Journal of Heat and Mass Transfer, 100: 199-207. https://doi.org/10.1016/j.ijheatmasstransfer.2016.04.081

[15] Xie, G., Wang, Q., Sunden, B. (2009). Parametric study and multiple correlations on air-side heat transfer and friction characteristics of fin-and-tube heat exchangers with large number of large-diameter tube rows. Applied Thermal Engineering, 29(1): 1-16. https://doi.org/10.1016/j.applthermaleng.2008.01.014

[16] Du, X., Feng, L., Li, L., Yang, L., Yang, Y. (2014). Heat transfer enhancement of wavy finned flat tube by punched longitudinal vortex generators. International Journal of Heat and Mass Transfer, 75: 368-380. https://doi.org/10.1016/j.ijheatmasstransfer.2014.03.081

[17] Duan, F., Song, K., Li, H., Chang, L., Zhang, Y., Wang, L. (2016). Numerical study of laminar flow and heat transfer characteristics in the fin side of the intermittent wavy finned flat tube heat exchanger. Applied Thermal Engineering, 103: 112-127. https://doi.org/10.1016/j.applthermaleng.2016.04.081

[18] Bejan, A. (1993). Heat Transfer. John Wiley \& Sons, Inc., New York.

[19] Gnielinski, V. (1976). New equations for heat and mass transfer in turbulent pipe and channel flow. International Journal of Chemical Engineering, 16(2): 359-367.

[20] Moffat, R.J. (1988). Describing the uncertainties in experimental results. Experimental Thermal and Fluid Science, 1(1): 3-17. https://doi.org/10.1016/08941777(88)90043-x

[21] Ray, D.R., Das, D.K. (2014). Superior performance of nanofluids in an automotive radiator. Journal of Thermal Science and Engineering Applications, 6(4): 041002. https://doi.org/10.1115/1.4027302

\section{NOMENCLATURE}

h

1

$\mathrm{S}$

D

L

A

a"

V

$\mathrm{m}$

Q

c

$\mathrm{T}$

$\Delta \mathrm{T}$

$\mathrm{h}$

G

Re

$\operatorname{Pr}$

$\mathrm{Nu}$

U fin thickness, $\mathrm{mm}$

fin height, mm

fin length, $\mathrm{mm}$

fin spacing, $\mathrm{mm}$

diameter, $\mathrm{mm}$

length, mm

area, $\mathrm{m}^{2}$

linear surface, $\mathrm{m}^{2} / \mathrm{m}^{3}$

volumetric flow, $\mathrm{m}^{3} / \mathrm{s}$

mass flow, kg/s

heat transfer rate, $\mathrm{W}$

specific heat, $\mathrm{J} /\left(\mathrm{kg}-{ }^{\circ} \mathrm{C}\right)$

temperature, ${ }^{\circ} \mathrm{C}$

temperature difference, ${ }^{\circ} \mathrm{C}$

convective coefficient, $\mathrm{W} /\left(\mathrm{m}^{2}-{ }^{\circ} \mathrm{C}\right)$

mass air flow, kg/s-m ${ }^{2}$

Reynolds number

Prandtl number

Nusselt number

overall heat transfer coefficient, $\mathrm{W} /\left(\mathrm{m}^{2}-{ }^{\circ} \mathrm{C}\right)$

\section{Greek symbols}

$\rho$

$\eta$

$\mu$

$\varepsilon$ density, $\mathrm{m}^{3} / \mathrm{kg}$

efficiency, $\%$

dynamic viscosity, $\mathrm{kg} \cdot \mathrm{m}^{-1} \cdot \mathrm{s}^{-1}$

uncertainty, \% 


\section{Subscripts}

ref

finned $\mathrm{f}$

1

$\mathrm{t}$

$\mathrm{T}$

w
Referential section

Finned section

frontal

longitudinal

external tube

total sectioned

water side $\mathrm{h}$

air side

finned surface

hydraulic parameter

water outlet

water inlet

air inlet

air outlet

$\mathrm{AO}$

Tn

" $n$ " temperature 